ISSN = 1980-993X - doi:10.4136/1980-993X
www.agro.unitau.br/ambi-agua
E-mail: ambi-agua@agro.unitau.br
Tel.: (12) 3625-4116

\title{
Capacidade de infiltração de água em solos sob diferentes usos e práticas de manejo agrícola \\ (doi:10.4136/ambi-agua.97)
}

\author{
Adilson Pinheiro' ${ }^{1}$ Lizandra Poeta Teixeira ${ }^{2}$; Vander Kaufmann ${ }^{3}$ \\ Universidade Regional de Blumenau \\ E-mail: pinheiro@furb.br ; lilioceano@yahoo.com.br²; ambitec@bol.com.br ${ }^{2}$
}

\section{RESUMO}

O conhecimento das propriedades físicas e hidráulicas do solo é de fundamental importância para o uso e manejo apropriado do solo e para o entendimento do processo dinâmico do movimento de água e de solutos deste. Este trabalho tem por finalidade determinar a capacidade de infiltração dos solos da Bacia experimental do ribeirão Concórdia, localizada no município de Lontras em Santa Catarina. Os ensaios de infiltração foram realizados com infiltrômetro de anéis concêntricos com diâmetros de 25 e $50 \mathrm{~cm}$, em vinte pontos amostrais que apresentam diferentes usos da terra e práticas de manejo agrícola. As capacidades de infiltração iniciais ajustadas pela equação de Horton variaram entre 0,8 (pastagem) e 5,0 $\mathrm{cm} \mathrm{min}^{-1}$ (floresta de Pinus e cultivo de mandioca). Nas áreas de pastagem, a infiltração inicial ajustada foi de 0,8 e $0,9 \mathrm{~cm} \mathrm{~min}^{-1}$. Com relação aos valores mínimos, eles variaram entre 0,01 (pastagem perene) e $0,3 \mathrm{~cm} \mathrm{~min}^{-1}$ (milho em cultivo mínimo). Nas áreas florestais, as infiltrações mínimas variaram entre 0,05 e $0,15 \mathrm{~cm} \mathrm{~min}^{-1} \mathrm{e}$, nas áreas de pastagens, foi igual a $0,01 \mathrm{~cm} \mathrm{~min}^{-1}$.

Palavras-chave: Manejo de bacias; propriedades físicas do solo; movimento de água no solo.

\section{Water infiltration capacity under different land uses and agricultural management practices}

\begin{abstract}
Knowledge of physical and hydraulic properties of soil is important for the appropriate use and management of soil, and for the understanding of dynamic movement process of water and solutes. This study aims to determine the soil infiltration capacity of the Concordia Experimental Basin, located in the municipality of Lontras in Santa Catarina state. The infiltration tests were performed with the concentric ring infiltrometer, with a diameter of 25 and $50 \mathrm{~cm}$ on twenty sampling points showing different uses of land and agricultural management practices. The initial capacity of infiltration, calculated by Horton's equation, ranged from 0.8 (pasture) to $5.0 \mathrm{~cm} \mathrm{~min}^{-1}$ (pine forest and cassava planting). In pasture areas, the initial infiltration ranged from 0.8 to $0.9 \mathrm{~cm} \mathrm{~min}^{-1}$. Regarding the minimum value, they ranged from 0.01 (perennial pasture) to $0.3 \mathrm{~cm} \mathrm{~min}^{-1}$ (minimum tillage for corn). In forest areas, the minimum infiltration varied between 0.05 and $0.15 \mathrm{~cm} \mathrm{~min}^{-1}$ and in the areas of pasture, it was equal to $0.01 \mathrm{~cm} \mathrm{~min}^{-1}$.
\end{abstract}

Keywords: Watershed management; soil physical properties; water movements in soil.

\section{INTRODUÇÃO}

A dinâmica da água no solo é um processo contínuo que controla o movimento dos elementos químicos que intervêm nos processos de formação e evolução dos solos, na 
PINHEIRO, A.; TEIXEIRA, L. P.; KAUFMANN, V. Capacidade de infiltração de água em solos sob diferentes usos e práticas de manejo agrícola. Ambi-Agua, Taubaté, v. 4, n. 2, p. 188-199, 2009. (doi:10.4136/ambiagua.97)

disponibilidade de nutrientes para as plantas e na satisfação da demanda hídrica (Maciel Netto et al., 2000). Esse movimento é diretamente dependente das características físico-hídricas do solo e pode ser descrito pela taxa de infiltração e pela condutividade hidráulica. Este último parâmetro representa a facilidade que o fluido tem para percolar através do solo (Wang et al., 1998).

Segundo Guerra (2000) e Carvalho (2002), a taxa de infiltração e a retenção de água pelo solo são importantes, pois auxiliam na definição de políticas de proteção e de conservação do solo e da água, planejamento de sistemas de irrigação e drenagem, bem como na composição de uma imagem mais real da retenção, movimento, redistribuição e conservação da água no solo.

A compreensão e a avaliação da capacidade de armazenamento de água no solo, bem como os fluxos que ocorrem tanto na superfície (infiltração e evaporação) quanto na profundidade do solo (drenagem interna), são importantes quando se trata da irrigação, drenagem, erosão, biologia da fauna e flora desse solo, lixiviação de elementos químicos, poluição do solo e da água, entre outros aspectos.

Libardi (2005) descreve que durante o processo de infiltração, estando o solo inicialmente seco, a capacidade de infiltração tende a decrescer com o tempo, atingindo um valor final, conhecido como capacidade de infiltração mínima. Pode ser considerada a propriedade que melhor reflete as condições físicas do solo, sua qualidade e estabilidade estrutural (Bertol et al., 2000; Angelotti Netto e Fernandes, 2005).

O processo de infiltração depende, em maior ou menor grau, de diversos fatores. Rawls et al. (1996) classificam em quatro categorias os fatores que interferem na infiltração: os ligados ao solo, que incluem a textura do solo (Silva e Kato, 1997), massa específica (Sales et al., 1999), teor de matéria orgânica, porosidade (Everts e Kanwar, 1992) e tipo de argila e químicas, além da umidade (Araújo Filho e Ribeiro, 1996), capacidade de retenção e a condutividade hidráulica.

Os fatores relacionados à superfície interferem no movimento da água através da interface ar-solo. $\mathrm{O}$ manejo do solo afeta a capacidade de infiltração à medida que interfere nas propriedades do solo e nas condições da superfície (cultivos agrícolas e irrigação) e nos fatores naturais que incluem precipitação, mudança de estação, umidade e temperatura (Cecilio, 2002). Alves e Cabeda (1999) determinaram a capacidade de infiltração em um Argissolo Vermelho-escuro, submetido ao preparo convencional e ao sistema plantio direto, usando chuva simulada com duas intensidades. Os resultados mostraram que o preparo convencional favoreceu o selamento superficial do solo, refletindo, assim, uma maior taxa de decréscimo da infiltração, menor infiltração acumulada e menor taxa constante de infiltração. O preparo convencional apresentou capacidade de infiltração $41 \%$ inferior à encontrada para o plantio direto.

Câmara e Klein (2005), estudando o efeito da escarificação nas propriedades de um Latossolo Vermelho Distrófico típico, constataram que a capacidade inicial, bem como a final de infiltração, aos 120 minutos, foi afetada pelo manejo do solo, observando-se uma diferença na capacidade inicial de infiltração a favor do plantio direto escarificado de 2,2 vezes e na taxa final de 3,77 vezes. O plantio direto apresentou uma taxa final de infiltração de $26,49 \mathrm{~mm}$ $\mathrm{h}^{-1}$ e o plantio direto escarificado de $99,99 \mathrm{~mm} \mathrm{~h}^{-1}$, sendo que o efeito da escarificação é constatado pela maior capacidade de infiltração.

A maioria dos estudos realizados sobre o efeito do uso da terra e das práticas de manejo agrícolas é realizadas em parcelas experimentais, em que as condições de contorno e as técnicas empregadas são bem controladas. Em uma bacia hidrográfica, as ações dos produtores agrícolas podem ser diferentes daquelas desenvolvidas em parcelas experimentais. Assim, este trabalho teve por finalidade determinar a capacidade de infiltração dos solos da Bacia experimental do ribeirão Concórdia, localizada no município de Lontras em Santa 
PINHEIRO, A.; TEIXEIRA, L. P.; KAUFMANN, V. Capacidade de infiltração de água em solos sob diferentes usos e práticas de manejo agrícola. Ambi-Agua, Taubaté, v. 4, n. 2, p. 188-199, 2009. (doi:10.4136/ambiagua.97)

Catarina, em função do tipo de uso da terra e do manejo agrícola. São ajustadas equações de infiltração de água no solo, as quais permitem compreender a evolução da capacidade de infiltração ao longo do tempo, em diferentes condições de manejo de solo agrícola. Estas condições são estabelecidas pelos produtores em suas práticas correntes. Isso significa que não são necessariamente empregadas as técnicas agrícolas recomendadas com base no conhecimento científico desenvolvido.

\section{MATERIAL E METODOS}

O estudo foi desenvolvido na bacia experimental do ribeirão Concórdia, localizada no município de Lontras (Figura 1), afluente do rio Lontras, Bacia do Itajaí, e está inserida entre as 7 microbacias monitoradas pelo Projeto de Recuperação Ambiental e de Apoio ao Pequeno Produtor Rural (PRAPEM/MICROBACIAS) e pela rede de pesquisa em bacias representativas e experimentais no Bioma da Mata Atlântica, na região sul do Brasil, denominado projeto MATASUL.

A bacia do ribeirão Concórdia possui uma área de drenagem de $30,74 \mathrm{~km}^{2}$. De acordo com a classificação de Thornthwaite, a região climática onde está inserida a bacia é definida como sendo clima Mesotérmico Úmido do tipo B3 B'3 ra', sem estação seca definida e com precipitações anuais entre 1600 a 1800 mm. De acordo com Köeppen, o clima é do tipo Cfa. A vegetação original da área pertence à Floresta Ombrófila Densa. Atualmente, os principais usos na bacia são mata nativa $(47,61 \%)$, pastagem $(20,35 \%)$ e milho $(9,29 \%)$. Na bacia são utilizados diferentes tipos de manejo do solo, tais como plantio direito, cultivo mínimo e plantio convencional. Neste último, ocorrem operações com grande aradora seguido de operações com grade niveladora. Os principais solos que caracterizam a região da Bacia do Ribeirão Concórdia são Gleissolo háplico Ta alumínico típico (Gxva) Cambissolo húmico alumínico típico (Cha), Cambissolo háplico Ta distrófico típico (Cxvd), Alissolo crômico órtico típico, Cambissolo háplico alumínico típico (Cxa) e Argissolo vermelho-amarelo (PVAal).

O estudo foi desenvolvido a partir de ensaios de infiltração realizados em 20 pontos amostrais (Figura 1), localizados em solos Cambissolo háplico alumínico típico (Cxa), Argissolo vermelho-amarelo (PVAal) e Gleissolo háplico Ta alumínico típico (Gxva). A escolha de cada ponto levou em consideração a facilidade e permissão de acesso e os tipos de uso do solo e do manejo agrícola desenvolvidos. Eles foram sendo escolhidos à medida que as amostragens e ensaios físicos iam sendo realizados. Detalhes dos pontos amostrais são apresentados na Tabela 1.

A capacidade de infiltração foi determinada pelo método dos anéis concêntricos. $\mathrm{O}$ procedimento seguiu as recomendações descritas por Paiva e Paiva (2003) e consistiu na utilização de dois cilindros metálicos de 25 e $50 \mathrm{~cm}$ de diâmetro respectivamente e ambos com $30 \mathrm{~cm}$ de altura e $0,5 \mathrm{~cm}$ de espessura. Os cilindros foram instalados no solo com o auxílio de uma marreta a uma profundidade de $15 \mathrm{~cm}$, tendo-se inserido o cilindro menor no interior do cilindro maior. Em seguida, adicionou-se água, simultaneamente, nos dois anéis. A colocação de água em ambos os cilindros foi para que a infiltração ocorresse de forma vertical.

A altura da lâmina de água colocada no cilindro interior variou entre 6 e $8 \mathrm{~cm}$, medida com o auxílio de uma régua graduada colocada na parte interna do cilindro menor. As medições da água foram feitas nos intervalos de tempo de 1, 2, 3, 4, 5, 10, 15, 20, 30, 45, 60, $70,80,90,110$ e 120 minutos.

No momento em que a água atingiu um nível limite inferior, estabelecido em cerca de 2 $\mathrm{cm}$, foi recolocada água nos dois cilindros, de forma a atingir o limite superior estabelecido para o experimento. Para cada intervalo de tempo, foi determinada a quantidade de água infiltrada. 
PINHEIRO, A.; TEIXEIRA, L. P.; KAUFMANN, V. Capacidade de infiltração de água em solos sob diferentes usos e práticas de manejo agrícola. Ambi-Agua, Taubaté, v. 4, n. 2, p. 188-199, 2009. (doi:10.4136/ambiagua.97)

Em cada ponto amostral foram realizados dois ensaios de infiltração visando a estabelecer uma reprodutibilidade. Em seguida, as capacidades de infiltração dos ensaios foram usadas no ajuste das equações de Horton e a de Kostiakov. No primeiro caso, foram determinados os parâmetros $\mathrm{i}_{\mathrm{c}}, \mathrm{i}_{\mathrm{o}} \mathrm{e} \kappa$. Este último é igual à expressão $\mathrm{e}^{-\mathrm{k}}$, de modo que a equação Horton pode ser expressa por:

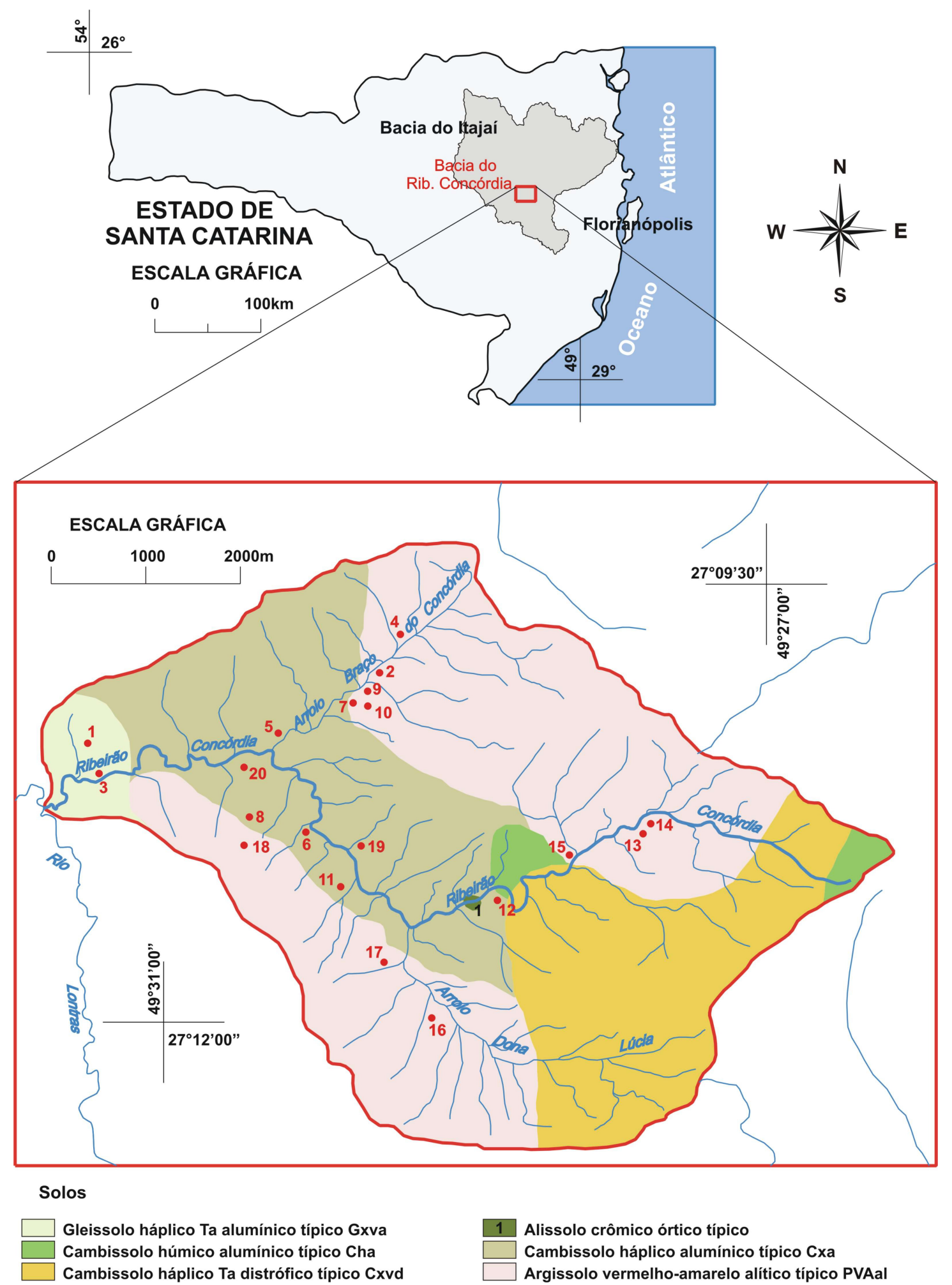

Figura 1. Bacia do Ribeirão Concórdia em Lontras-SC com os respectivos tipos de solo e pontos de amostragem. 
PINHEIRO, A.; TEIXEIRA, L. P.; KAUFMANN, V. Capacidade de infiltração de água em solos sob diferentes usos e práticas de manejo agrícola. Ambi-Agua, Taubaté, v. 4, n. 2, p. 188-199, 2009. (doi:10.4136/ambiagua.97)

Tabela 1. Características dos pontos amostrais.

\begin{tabular}{|c|c|c|c|c|}
\hline Ponto & $\begin{array}{c}\text { Altitude } \\
\text { (m) }\end{array}$ & Uso da terra & Práticas de manejo & Tipo de solo \\
\hline 1 & 275 & Pastagem perene & & Gxva \\
\hline 2 & 348 & Cultivo de Cereais (milho) & Cultivo mínimo & PVAal \\
\hline 3 & 324 & $\begin{array}{l}\text { Reflorestamento de Pínus spp. } \\
\text { com idade de } 3 \text { anos }\end{array}$ & & Gxva \\
\hline 4 & 354 & $\begin{array}{l}\text { Reflorestamento de Pínus spp. } \\
\text { com idade de } 19 \text { anos, com } \\
\text { sub-bosque }\end{array}$ & & PVAal \\
\hline 5 & 326 & Cultivo de Cereais (milho) & $\begin{array}{l}\text { Rotação de cultura (milho e feijão), } \\
\text { plantio convencional }\end{array}$ & Cxa \\
\hline 6 & 362 & Cultivo de Cereais (milho) & Sem rotação, plantio direto & Cxa \\
\hline 7 & 368 & $\begin{array}{l}\text { Reflorestamento de } \\
\text { Eucalyptus spp. e pastagem } \\
\text { perene }\end{array}$ & & PVAal \\
\hline 8 & 355 & Cultivo de Cereais (milho) & Sem rotação, plantio convencional & Cxa \\
\hline 9 & 376 & Cultivo de Cereais (milho) & Sem rotação, plantio convencional & PVAal \\
\hline 10 & 384 & $\begin{array}{c}\text { Mata nativa com alteração de } \\
\text { pastoreio }\end{array}$ & & PVAal \\
\hline 11 & 371 & Cultivo de Cereais (milho) & Sem rotação, plantio convencional & $\mathrm{Cxa}$ \\
\hline 12 & 432 & $\begin{array}{l}\text { Reflorestamento de } \\
\text { Eucalyptus spp. com idade de } \\
9 \text { anos, com sub-bosque }\end{array}$ & & Cxa \\
\hline 13 & 486 & Cultivo de Raiz (mandioca) & Cultivo mínimo & PVAal \\
\hline 14 & 486 & Pastagem perene & & PVAal \\
\hline 15 & 435 & Cultivo de Cereais (milho) & $\begin{array}{c}\text { Rotação de cultura (milho, feijão e } \\
\text { adubação verde) } \\
\text { Plantio Direto }\end{array}$ & PVAal \\
\hline 16 & 438 & Cultivo de Cebola & $\begin{array}{c}\text { Rotação de cultura (Cebola e } \\
\text { Milho) } \\
\text { Plantio Convencional }\end{array}$ & PVAal \\
\hline 17 & 427 & Cultivo de Fumo & Plantio Convencional & PVAal \\
\hline 18 & 470 & Área abandonada & & PVAal \\
\hline 19 & 379 & $\begin{array}{c}\text { Reflorestamento de } \\
\text { Eucalyptus spp. com idade de } \\
13 \text { anos sobre pastagem } \\
\text { perene }\end{array}$ & & Cxa \\
\hline 20 & 354 & Mata nativa & & $\mathrm{Cxa}$ \\
\hline
\end{tabular}

$\mathrm{i}=\mathrm{i}_{\mathrm{c}}+\left(\mathrm{i}_{0}-\mathrm{i}_{\mathrm{c}}\right) \mathrm{\kappa}^{\mathrm{t}}$

em que:

$\mathrm{i}=$ capacidade de infiltração $\left(\mathrm{cm} \mathrm{min}^{-1}\right)$,

$\mathrm{i}_{\mathrm{c}}=$ capacidade de infiltração mínima $\left(\mathrm{cm} \mathrm{min}^{-1}\right)$,

$\mathrm{i}_{0}=$ capacidade de infiltração inicial $\left(\mathrm{cm} \mathrm{min}^{-1}\right)$,

$\mathrm{t}=$ tempo percorrido desde a saturação superficial do solo (min),

$\kappa=$ constante que depende do tipo de solo. 
PINHEIRO, A.; TEIXEIRA, L. P.; KAUFMANN, V. Capacidade de infiltração de água em solos sob diferentes usos e práticas de manejo agrícola. Ambi-Agua, Taubaté, v. 4, n. 2, p. 188-199, 2009. (doi:10.4136/ambiagua.97)

A equação de Kostiakov é expressa por:

$\mathrm{i}=\alpha \mathrm{t}^{-\beta}$

em que:

$\mathrm{i}=$ capacidade de infiltração $\left(\mathrm{cm} \mathrm{min}^{-1}\right)$

$\alpha=$ constante representativa da capacidade de infiltração inicial,

$\mathrm{t}=$ tempo percorrido desde $\mathrm{o}$ inicio da infiltração $(\mathrm{min})$,

$\beta=$ constante que depende do tipo de solo

Os valores dos parâmetros da equação de Horton foram determinados por otimização no qual se busca o maior valor do coeficiente de correlação. Esse coeficiente é obtido entre os valores das capacidades de infiltração medidos nos ensaios de infiltração e aqueles calculados pela equação. Os parâmetros da equação de Kostiakov foram obtidos diretamente por ajuste da equação potência.

\section{RESULTADOS E DISCUSSÃO}

A curva que descreve infiltração caracteriza as forças capilares e gravitacionais. O efeito de cada força varia ao longo do tempo. No início do processo de infiltração, as forças capilares são preponderantes, podendo-se desprezar as forças gravitacionais. Após um longo tempo de infiltração, a situação se inverte, de modo que as forças capilares podem ser desprezadas diante da magnitude das forças gravitacionais. A curva de capacidade de infiltração evolui em função das características hidrodinâmicas e tendem a retas quando o fluxo de infiltração se aproxima do regime estacionário.

Os parâmetros da equação de Horton representam a relação entre as forças capilares e as forças gravitacionais. $\mathrm{O}$ valor de ic representa o fluxo de infiltração em regime estacionário. A Tabela 2 apresenta os parâmetros ajustados às equações de Kostiakov e Horton.

$\mathrm{O}$ parâmetro $\mathrm{i}_{\mathrm{o}}$ representa a infiltração máxima, que ocorre no início da infiltração e o parâmetro $i_{c}$ representa a mínima que é observada quando o solo se encontra na condição de saturação. Os valores ajustados para $i_{o}$ variaram entre $0,8 \mathrm{~cm} \mathrm{~min}^{-1}$ (pastagem) e 5,0 $\mathrm{cm} \mathrm{min}^{-1}$ (floresta de Pinus e plantio de mandioca). Nas áreas com coberturas florestais, os valores desse parâmetro foram superiores a 2,2 $\mathrm{cm} \mathrm{min}^{-1}$. Ressalta-se que nas áreas de pastagem a infiltração inicial ajustada foi de 0,8 e $0,9 \mathrm{~cm} \mathrm{~min}^{-1}$.

Os valores de $i_{c}$ variaram entre $0,01 \mathrm{~cm} \mathrm{~min}^{-1}$ (pastagem perene) e $0,3 \mathrm{~cm} \mathrm{~min}^{-1}$ (milho em cultivo mínimo). Nas áreas florestais, as infiltrações mínimas variaram entre 0,05 e 0,15 $\mathrm{cm} \min ^{-1}$ e nas áreas de pastagens, $\mathrm{i}_{\mathrm{c}}$ foi igual a $0,01 \mathrm{~cm} \mathrm{~min}^{-1}$. Neste ultimo caso, supõe-se que as raízes das gramíneas dificultam o movimento vertical da água na camada superficial do solo, reduzindo significativamente a capacidade de infiltração.

Foram obtidos valores de $\kappa$ variando entre 0,6 e 0,9 . Esse parâmetro é igual a $\mathrm{e}^{-\mathrm{k}}$, em que o valor de k representa a velocidade de decaimento da capacidade de infiltração. Desse modo, os menores valores de $\kappa$ indicam que capacidade de infiltração reduz-se mais rapidamente do que nos casos em que ele é mais elevado. $\mathrm{O}$ valor de $\kappa$ de 0,9 foi ajustado à área com cultivo de milho, sem rotação de cultura. Na área abandonada, o valor ajustado de $\kappa$ foi elevado, sendo igual a 0,8. Esses valores assim como os demais, não apresentam correlação com os usos e cobertura da terra.

O parâmetro $\alpha$, representativo da capacidade de infiltração inicial, ajustado à equação de Kostiakov variou entre $0,032 \mathrm{~cm} \mathrm{~min}^{-1}$ (pastagem perene) e 2,219 $\mathrm{cm} \mathrm{min}^{-1}$ (cultivo de cereais com cultivo mínimo). Os valores são diferentes de $\mathrm{i}_{\mathrm{o}}$ ajustados à equação de Horton. Os 
PINHEIRO, A.; TEIXEIRA, L. P.; KAUFMANN, V. Capacidade de infiltração de água em solos sob diferentes usos e práticas de manejo agrícola. Ambi-Agua, Taubaté, v. 4, n. 2, p. 188-199, 2009. (doi:10.4136/ambiagua.97)

valores da equação de Kostiakov são menores, cerca de 3 vezes. Esta diferença pode ter sido produzida pelo tipo de equação utilizada. A equação de Horton é uma equação exponencial, que representa melhor a evolução da infiltração no início do processo de infiltração (Alves Sobrinho et al., 2003). No caso da equação de Kostiakov, do tipo potência, a evolução do processo de infiltração no inicio não é bem descrita. Assim, o valor de $\alpha$ não pode ser considerado como o valor efetivo da capacidade de infiltração inicial.

Tabela 2. Parâmetros das equações de Horton e Kostiakov.

\begin{tabular}{|c|c|c|c|c|c|c|c|c|}
\hline \multirow{2}{*}{$\begin{array}{c}\text { Ponto } \\
\text { Amos- } \\
\text { tral }\end{array}$} & \multirow[t]{2}{*}{ Uso da terra } & \multicolumn{4}{|c|}{ Horton } & \multicolumn{3}{|c|}{ Kostiakov } \\
\hline & & $\begin{array}{c}\mathbf{i}_{\mathbf{o}} \\
\left(\mathrm{cm} \mathrm{\operatorname {min } ^ { - 1 }}\right)\end{array}$ & $\begin{array}{c}\mathbf{i}_{\mathrm{c}} \\
\left(\mathrm{cm} \mathrm{min}^{-1}\right)\end{array}$ & $\kappa$ & $\mathbf{R}^{2}$ & $\alpha$ & $\beta$ & $\mathbf{R}^{2}$ \\
\hline 1 & Pastagem perene & 0,9 & 0,01 & 0,6 & 0,54 & 0,032 & $-0,53$ & 0,355 \\
\hline 2 & Cultivo de Cereais (milho) & 4,2 & 0,3 & 0,7 & 0,58 & 2,219 & $-0,57$ & 0,529 \\
\hline 3 & $\begin{array}{l}\text { Reflorestamento de Pínus spp. } \\
\text { com idade de } 3 \text { anos } \\
\text { Reflorestamento de Pínus spp. } \\
\text { com idade de } 19 \text { anos, com sub- }\end{array}$ & 5 & 0,15 & 0,7 & 0,20 & 1,29 & $-0,62$ & 0,493 \\
\hline 4 & bosque & 1,4 & 0,05 & 0,7 & 0,48 & 0,359 & $-0,49$ & 0,477 \\
\hline 5 & Cultivo de Cereais (milho) & 1,8 & 0,05 & 0,7 & 0,17 & 0,297 & $-0,44$ & 0,192 \\
\hline 6 & $\begin{array}{l}\text { Cultivo de Cereais (milho) } \\
\text { Reflorestamento de Eucalyptus }\end{array}$ & 1,8 & 0,03 & 0,7 & 0,87 & 0,984 & $-0,92$ & 0,902 \\
\hline 7 & spp. e pastagem perene & 2,2 & 0,05 & 0,7 & 0,29 & 0,39 & $-0,49$ & 0,1082 \\
\hline 8 & Cultivo de Cereais (milho) & 1,7 & 0,04 & 0,6 & 0,82 & 0,591 & $-0,63$ & 0,688 \\
\hline 9 & Cultivo de Cereais (milho) & 1,4 & 0,06 & 0,9 & 0,65 & 1,058 & $-0,55$ & 0,637 \\
\hline 10 & $\begin{array}{l}\text { Mata nativa com alteração de } \\
\text { pastoreio } \\
\text { Cultivo de Cereais (milho) }\end{array}$ & 3,5 & 0,06 & $\begin{array}{l}0,7 \\
0,7\end{array}$ & 0,34 & 0,718 & $-0,6$ & 0,409 \\
\hline 11 & & 2,5 & 0,06 & 5 & 0,83 & 1,526 & $-0,78$ & 0,782 \\
\hline & $\begin{array}{l}\text { Reflorestamento de Eucalyptus } \\
\text { spp. com idade de } 9 \text { anos, com }\end{array}$ & & & 0,7 & & & & \\
\hline 12 & sub-bosque & 3,3 & 0,09 & 5 & 0,80 & 2,21 & $-0,67$ & 0,835 \\
\hline 13 & Cultivo de Raiz (mandioca) & 6,5 & 0,09 & 0,6 & 0,46 & 1,763 & $-0,69$ & 0,56 \\
\hline 14 & Pastagem perene & 0,8 & 0,01 & 0,6 & 0,84 & 0,167 & $-0,65$ & 0,501 \\
\hline 15 & Cultivo de Cereais (milho) & 1,8 & 0,03 & 0,6 & 0,40 & 0,119 & $-0,3$ & 0,122 \\
\hline 16 & $\begin{array}{l}\text { Cultivo de Cebola } \\
\text { Cultivo de Fumo }\end{array}$ & 3,2 & 0,08 & $\begin{array}{l}0,7 \\
0,7\end{array}$ & 0,69 & 1,104 & $-0,58$ & 0,661 \\
\hline 17 & & 3,5 & 0,06 & 2 & 0,51 & 1,155 & $-0,66$ & 0,582 \\
\hline 18 & $\begin{array}{l}\text { Área abandonada } \\
\text { Reflorestamento de Eucalyptus } \\
\text { spp. com idade de } 13 \text { anos sobre }\end{array}$ & 4,1 & 0,15 & 0,8 & 0,38 & 1,52 & $-0,47$ & 0,434 \\
\hline 19 & pastagem perene & 4 & 0,15 & 0,6 & 0,86 & 1,905 & $-0,61$ & 0,822 \\
\hline 20 & Mata nativa & 3,3 & 0,09 & 0,7 & 0,84 & 1,664 & $-0,63$ & 0,588 \\
\hline
\end{tabular}

Por outro lado, foram determinadas as capacidades de infiltração em cada ponto amostral, para o tempo de $120 \mathrm{~min}$, com o emprego das equações de Kostiakov ajustadas. Para esse tempo a variação da capacidade de infiltração é pequena, podendo ser considerada como constante, representativa da condutividade hidráulica de saturação (Musy e Souter, 1991). Nesse tempo, obteve-se o valor médio da capacidade de infiltração em áreas com uso da terra com pastagem de $0,0197 \mathrm{~cm} \mathrm{~min}^{-1}$, com agricultura de $0,0403 \mathrm{~cm} \mathrm{~min}{ }^{-1}$ e com floresta de $0,0766 \mathrm{~cm} \mathrm{~min}^{-1}$.

A Figura 2 apresenta as capacidades de infiltração em áreas com cultivo de milho, nas quais são desenvolvidas diferentes práticas de manejo. As curvas foram geradas com as equações de Kostiakov ajustadas. Observa-se que a curva de capacidade de infiltração é mais elevada no manejo de cultivo mínimo (para o tempo de 120 min a capacidade de infiltração é de $0,1449 \mathrm{~cm} \mathrm{~min}^{-1}$ ) e a menor foi observada na área de plantio direto (para o tempo de 120 min a capacidade de infiltração é de $0,012 \mathrm{~cm} \mathrm{~min}^{-1}$ ). Entre as duas, encontram-se as curvas 
PINHEIRO, A.; TEIXEIRA, L. P.; KAUFMANN, V. Capacidade de infiltração de água em solos sob diferentes usos e práticas de manejo agrícola. Ambi-Agua, Taubaté, v. 4, n. 2, p. 188-199, 2009. (doi:10.4136/ambiagua.97)

de capacidade de infiltração das áreas com plantio convencional. Resultados similares foram encontrados por Anjos et al. (1994). Bertiol et al. (2001) determinaram capacidades de infiltração iniciais e finais mais elevadas em cultivo convencional do que em semeadura direta e em campo nativo pastejado.

Por outro lado, quando a capacidade de infiltração é medida por meio de simulador de chuva, em parcela experimental, obtém-se capacidade de infiltração sob plantio direto maior do que no plantio convencional. Tem sido justificado que no plantio direto, a existência da palhada na superfície do solo e o aparecimento de uma rede de macroporos contínuos em profundidade proporcionam um aumento da infiltração de água (Khan et al., 2001). No plantio direto, o solo encontra-se protegido por uma cobertura morta, o que aumenta a quantidade de água interceptada. A vegetação ainda amortece a energia de impacto das gotas de chuva, reduzindo a desagregação, a obstrução dos poros e o selamento superficial do solo. Além disto, a presença de cobertura vegetal na superfície também promove a redução da velocidade do escoamento superficial, aumentando o tempo de oportunidade para a infiltração, devido ao aumento da rugosidade hidráulica do percurso ao longo do qual ocorre o escoamento (Volk et al., 2004).

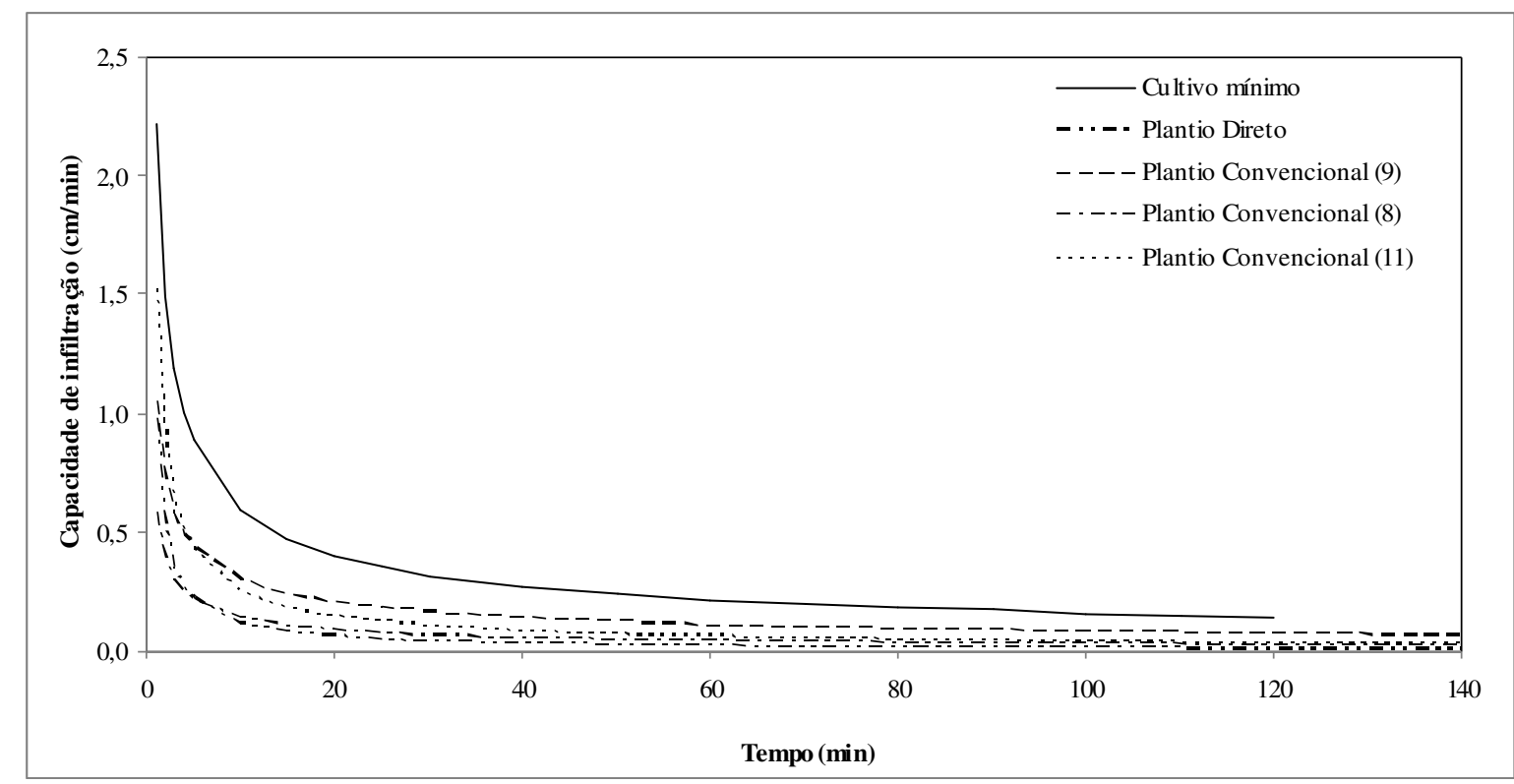

Figura 2. Capacidades de infiltração em cultivos de milho.

A Figura 3 apresenta as capacidades de infiltração de áreas com rotação de culturas. Observa-se que os dois pontos amostrais com plantio convencional apresentam capacidades de infiltração superiores ao plantio direto. O plantio convencional promove a movimentação do solo, desestruturando-o e favorecendo o processo de infiltração de água no solo.

A área com plantio direto apresenta capacidade de infiltração superior à área de pastagem, conforme pode ser observado na Figura 4. No entanto, é significativamente menor do que a capacidade de infiltração da área de reflorestamento com Pínus e em mata nativa. Constata-se que nas áreas florestadas, as capacidades de infiltração são similares.

$\mathrm{Na}$ Figura 5, apresenta-se outra comparação da capacidade de infiltração da mata nativa com o plantio convencional, plantio direto e pastagem. Nota-se que a mata nativa apresenta capacidade de infiltração superior à dos demais usos do solo.

Nota-se que foram registradas diferenças na capacidade de infiltração para os diferentes usos e manejos do solo. Na mata nativa houve uma tendência de estabilização a partir dos 60 minutos, ao passo que, no cultivo convencional, direto e de pastagem, a estabilização teve inicio a partir dos 30 minutos. Essa situação também foi observada por Anjos et al. (1994), 
PINHEIRO, A.; TEIXEIRA, L. P.; KAUFMANN, V. Capacidade de infiltração de água em solos sob diferentes usos e práticas de manejo agrícola. Ambi-Agua, Taubaté, v. 4, n. 2, p. 188-199, 2009. (doi:10.4136/ambiagua.97)

para um cambissolo bruno húmico álico e para um Argissolo vermelho-escuro distrófico. Outros trabalhos como os de Leite e Medina (1984) e Corrêa (1985) também constataram que a infiltração é maior em área de mata nativa do que em solos com diferentes cultivos.

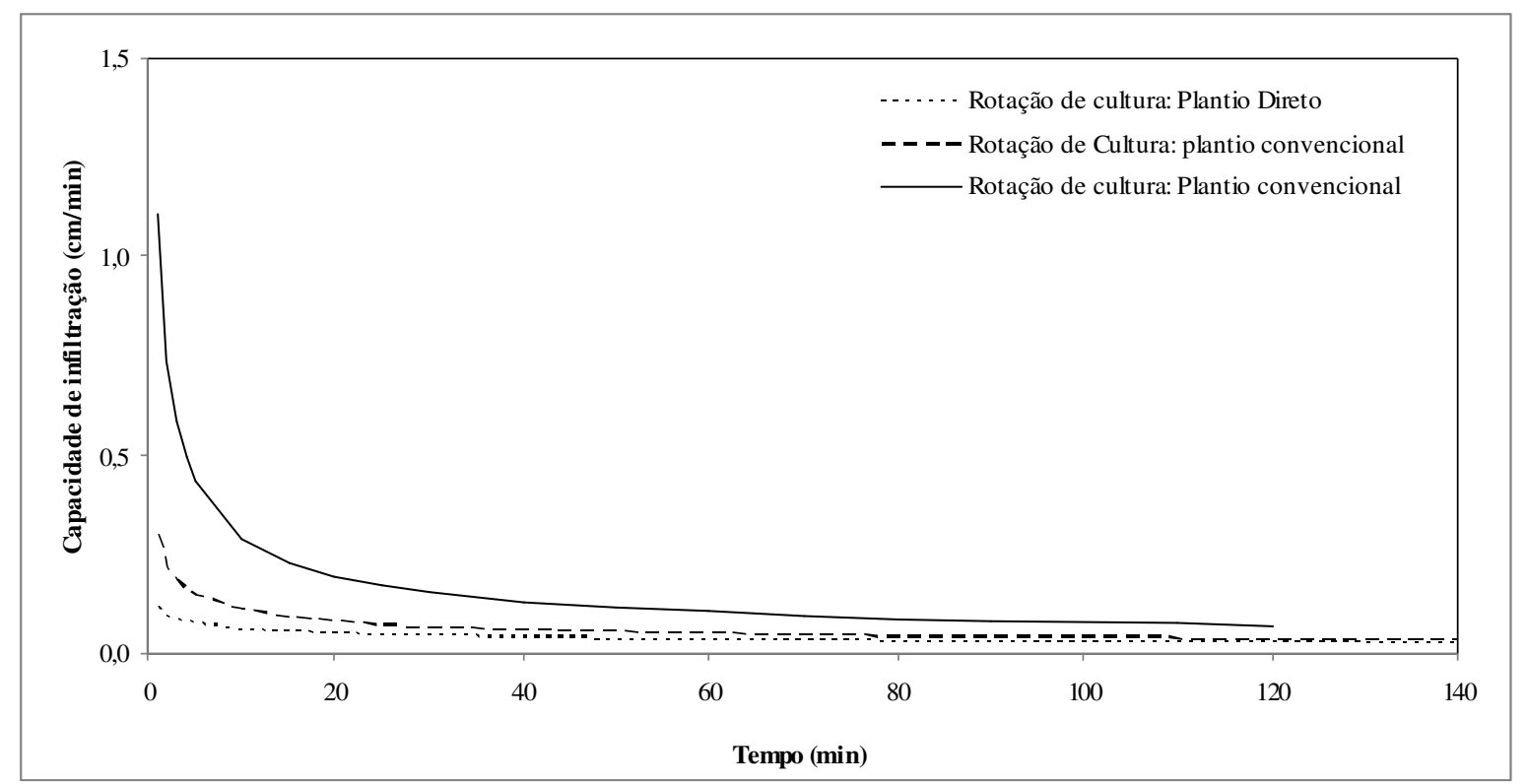

Figura 3. Capacidade de infiltração em áreas com rotação de culturas para diferentes manejos.

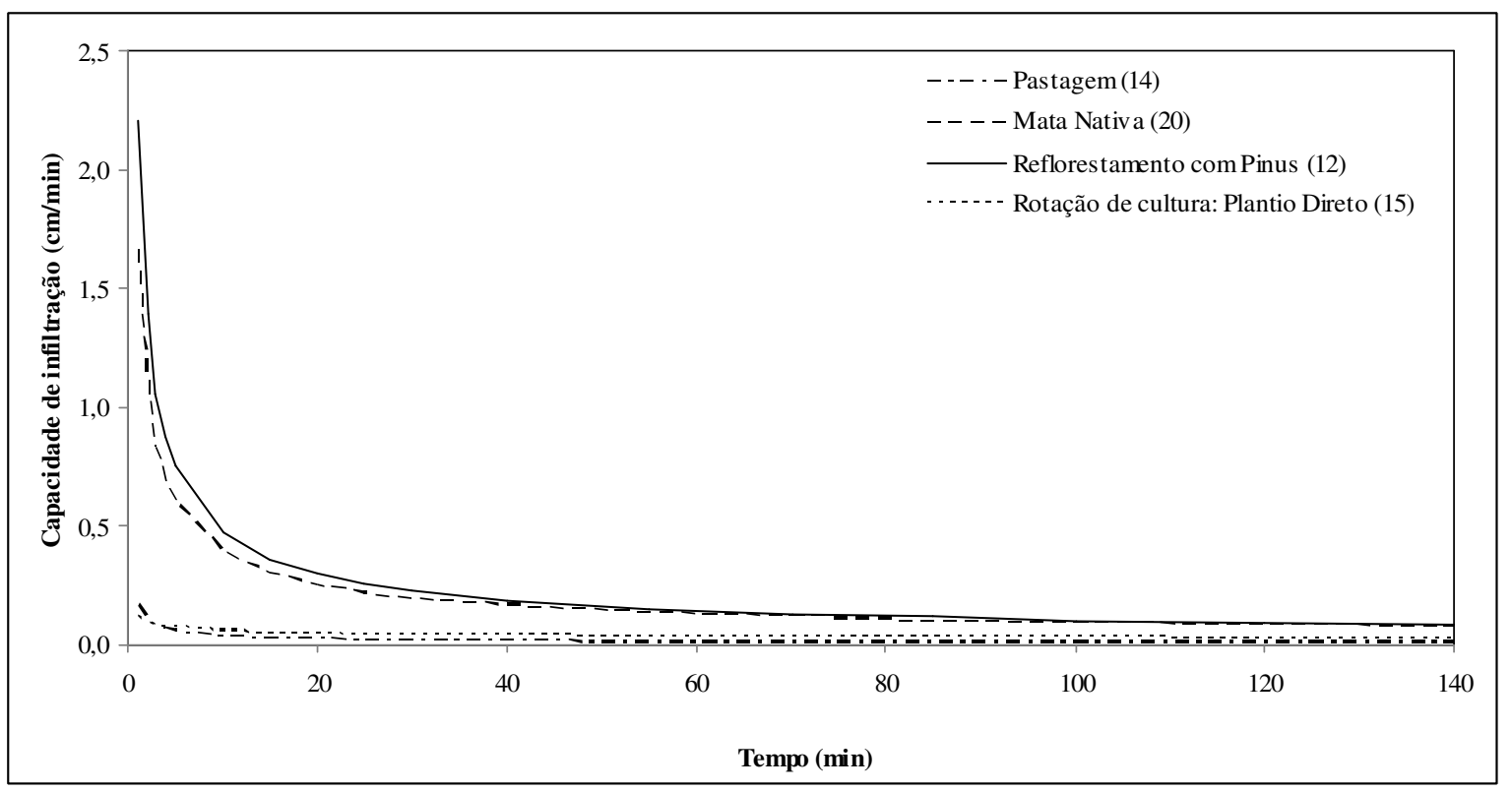

Figura 4. Capacidade de infiltração em áreas florestais, pastagem e plantio direto. 
PINHEIRO, A.; TEIXEIRA, L. P.; KAUFMANN, V. Capacidade de infiltração de água em solos sob diferentes usos e práticas de manejo agrícola. Ambi-Agua, Taubaté, v. 4, n. 2, p. 188-199, 2009. (doi:10.4136/ambiagua.97)

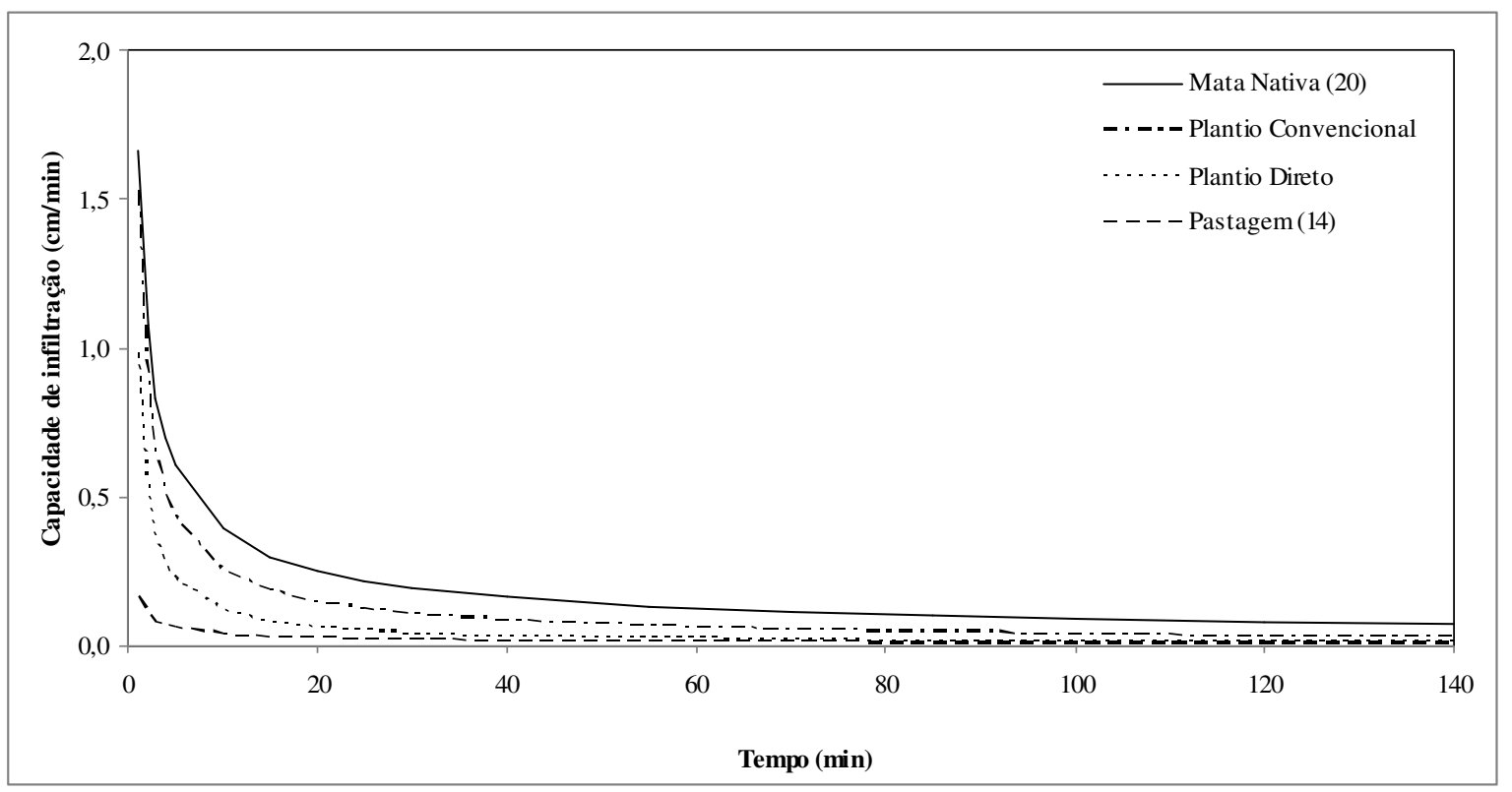

Figura 5. Capacidade de infiltração em mata nativa, plantio convencional e direto e pastagem.

\section{CONCLUSÕES}

- Nos pontos amostrais em que a atividade desenvolvida é o cultivo de milho e, levandose em consideração as diferentes práticas de manejo, o maior valor observado de capacidade de infiltração foi para o cultivo mínimo e o menor para as áreas com plantio direto.

- Nas áreas com rotação de culturas, a capacidade de infiltração foi superior para o plantio convencional, devido à movimentação do solo ocasionado.

- Comparando-se as diferentes atividades exercidas nos pontos amostrais, observou-se que os maiores valores de capacidade de infiltração se localizam nas matas nativas e os menores, nos locais onde a atividade é a pastagem.

\section{AGRADECIMENTOS}

Agradecemos ao MCT/FINEP/CT-Hidro-CNPq, Edital 04/2005 Bacias Representativas, convênio 3490/05, pelo financiamento da pesquisa, ao CNPq (Proc 301156/2008-5) pela concessão da bolsa de produtividade do primeiro autor e de mestrado do segundo e terceiro autores e aos revisores pelas expressivas recomendações que vieram a enriquecer este artigo.

\section{REFERÊNCIAS}

ALVES, M. C.; CABEDA, M. S. V. Infiltração de água em um podzólico Vermelho-Escuro sob dois métodos de preparo, usando chuva simulada com duas intensidades. Revista Brasileira de Ciências do Solo, Viçosa, v. 23, n. 4, p. 735-761, 1999.

ALVES SOBRINHO, T.; VITORINO, A. C. T.; SOUZA, L. C. F.; GONÇALVES, M. C.; CARVALHO, D. F. Infiltração de água no solo em sistemas de plantio direto e convencional. Revista Brasileira de Engenharia Agrícola e Ambiental, Campina Grande-PB, v. 7, n. 2, p. 191-196, 2003.

ANGELOTTI NETTO, A.; FERNANDES, E. J. Avaliação da taxa de infiltração de água em um latossolo vermelho submetido a dois sistemas de manejo. Irriga, Botucatu, v.10, n.2, p.107-115, maio-julho 2005. 
PINHEIRO, A.; TEIXEIRA, L. P.; KAUFMANN, V. Capacidade de infiltração de água em solos sob diferentes usos e práticas de manejo agrícola. Ambi-Agua, Taubaté, v. 4, n. 2, p. 188-199, 2009. (doi:10.4136/ambiagua.97)

ANJOS, J. T.; UBERTI, A. A. A.; VIZZOTTO, V. J.; LEITE, G. B.; KRIEGER, M. Propriedades físicas em solos sob diferentes sistemas de uso e manejo. Revista Brasileira de Ciência do Solo, Campinas, v. 18, p 139-145, 1994.

ARAÚJO FILHO, J. C.; RIBEIRO, M. R. Infiltração da água em cambissolos do baixio de Irecê (BA). Revista Brasileira de Ciência do Solo, Campinas, v. 20, p. 363- 370, 1996.

BERTOL, I.; ALMEIDA, J. A.; ALMEIDA, E. X.; KURTZ, C. Propriedades físicas do solo relacionadas a diferentes níveis de oferta de forragem Capim Elefante Anão cv Mott. Pesquisa Agropecuária Brasileira, Brasília, v. 35, n. 5, p. 1047-1054, 2000.

BERTOL, I.; BEUTLER, J. F.; LEITE, D.; BATISTELA, O. Propriedades físicas de um Cambissolo Húmico afetadas pelo tipo de manejo do solo. Scientia Agricola, Piracicaba, v. 58, n. 3, p. 555-560, 2001.

CÂMARA, R. C.; KLEIN, V. A. Escarificação em plantio direto como técnica de conservação do solo e da água. Revista Brasileira de Ciência do Solo, Campinas, v. 29, p. 789-796, 2005.

CARVALHO, L. A. Condutividade hidráulica do solo no campo: as simplificações do método do perfil instantâneo. 2002. Dissertação (Mestrado em Solos e Nutrição de Plantas) - Escola Superior de Agricultura "Luiz de Queiroz", Universidade de São Paulo, Piracicaba, 2002.

CECILIO, R. A. Aplicação da equação de Green-Ampt na modelagem da infiltração de água em Latossolo Vermelho-Amarelo estratificado. 2002. Dissertação (Mestrado em Engenharia Agrícola) - Programa de Pós-Graduação em Engenharia Agrícola, Universidade Federal de Viçosa, Viçosa, 2002.

CORRÊA, J. C. Efeito de métodos de cultivo em algumas propriedades físicas de um Latossolo Amarelo muito argiloso no Estado do Amazonas. Pesquisa Agropecuária Brasileira, Brasília, v. 20, n.11, p.1317-22, 1985.

EVERTS, C. J.; KANWAR, R. S. Interpreting tension-infiltrometer data for quantyfying soil macropores: some practical considerations. Transactions of the ASAE, Saint Joseph, v. 36, n. 2, p. 423-428, 1992.

GUERRA, H.C. Física dos solos. Campina Grande: UFPB, 2000.

KHAN, F. U. H.; TAHIR, A. R.; YULE, I. J. Intrinsic implication of different tillage practices on soil penetration resistance and crop growth. International Journal of Agriculture and Biology, v. 1, p. 23-26, 2001.

LEITE, J.A.; MEDINA, F.B. Efeito dos sistemas de manejo sobre as propriedades físicas de um Latossolo Amarelo do Amazonas. Pesquisa Agropecuária Brasileira, Brasília, v.19, n.8, p.1417-22, 1984.

LIBARDI, P. L. Dinâmica da água no solo. São Paulo: Editora Universidade de São Paulo, 2005.

MUSY, A.; SOUTER, M. Physique du Sol. Lausanne: Presses Polytechniques et Universitaires Romandes, 1991. 
PINHEIRO, A.; TEIXEIRA, L. P.; KAUFMANN, V. Capacidade de infiltração de água em solos sob diferentes usos e práticas de manejo agrícola. Ambi-Agua, Taubaté, v. 4, n. 2, p. 188-199, 2009. (doi:10.4136/ambiagua.97)

MACIEL NETTO, A. ; ANTONINO, A. C. D.; AUDRY, P.; CARNEIRO, C. J. G.; DALL'OLIO, A. Condutividade hidráulica não saturada de um podzólico amarelo da zona da mata norte de Pernambuco. Pesquisa Agropecuária Brasileira, Brasília, v. 35, n. 6, p.1221-1228, 2000.

PAIVA, J. B. D.; PAIVA, E. M. C. D. Hidrologia Aplicada à gestão de pequenas bacias hidrográficas. Porto Alegre: ABRH, 2003.

RAWLS, W. J.; DAVID, G.; VAN MULLEN, J. A.; WARD, T. J. Infiltration. In: AMERICAN SOCIETY of CIVIL ENGINEERS. Hydrology Handbook. 2. ed. New York: ASCE, 1996. p.75-124. (ASCE Manuals and Report on Engineering Practice, 28).

SALES, L. E. O.; FERREIRA, M. M.; OLIVEIRA, M. S.; CURI, N. Estimativa da velocidade de infiltração básica do solo. Pesquisa Agropecuária Brasileira, Brasília, v. 34, n. 11, p. 2091-2095, 1999.

SILVA, C.; KATO, E. Efeito do selamento superficial na condutividade hidráulica saturada da superfície de um solo sob cerrado. Pesquisa Agropecuária Brasileira, Brasília, v. 32, n. 2, p. 213- 220, 1997.

VOLK, L. B. S.; COGO, N. P.; STRECK E. V. Erosão hídrica influenciada por condições físicas de superfície e subsuperfície do solo resultantes do seu manejo, na ausência de cobertura vegetal. Revista Brasileira de Ciência do Solo, Campinas, v. 28, p. 763-774, 2004.

WANG, D.; YATES, S. R.; ERNST, F. F. Determining soil hydraulic properties using tension infiltrometers, time domain reflectometry, and tensiometers. Soil Science Society of America Journal, Madison, v. 62, n. 2, p. 318-325, 1998. 